\title{
Genetic correlations between mature cow weight and productive and reproductive traits in Nellore cattle
}

\author{
I.C. Regatieri, A.A. Boligon, F. Baldi and L.G. Albuquerque \\ Departamento de Zootecnia, Faculdade de Ciências Agrárias e Veterinárias, \\ Universidade Estadual Paulista, Jaboticabal, SP, Brasil \\ Corresponding author: I.C. Regatieri \\ E-mail: iregatieri@hotmail.com
}

Genet. Mol. Res. 11 (3): 2979-2986 (2012)

Received October 3, 2011

Accepted January 31, 2012

Published May 10, 2012

DOI http://dx.doi.org/10.4238/2012.May.10.4

\begin{abstract}
We investigated genetic associations between mature cow weight (MW) and weaning weight (WW), yearling weight (YW), weight gain from birth to weaning (GBW), weight gain from weaning to yearling (GWY), weaning hip height (WHH), yearling hip height (YHH), scrotal circumference (SC), and age at first calving (AFC). Data from 127,104 Nellore animals born between 1993 and 2006, belonging to Agropecuária Jacarezinho Ltda., were analyzed. (Co)variance components were obtained by the restricted maximum likelihood method, applying an animal model in a multi-traits analysis. The model included direct genetic and residual effects as random effects, the fixed effects of contemporary group, and the linear and quadratic effects of animal age at recording (except for AFC, GBW, and GWY) and age of cow at calving as covariates (except for MW). The numbers of days from birth to weaning and from weaning to yearling were included as covariates for GBW and GWY, respectively. Estimated direct heritabilities were $0.43 \pm 0.02(\mathrm{MW}), 0.33 \pm 0.01$ (WW), $0.36 \pm 0.01$ (YW), $0.28 \pm 0.02$ (GBW), $0.31 \pm 0.01$ (GWY), $0.44 \pm 0.02$ (WHH), $0.48 \pm 0.02(\mathrm{YHH}), 0.44 \pm 0.01(\mathrm{SC})$, and $0.16 \pm 0.03$ (AFC). Genetic
\end{abstract}


correlations between MW and productive traits were positive and of medium to high magnitude (ranging from $0.47 \pm 0.03$ to $0.71 \pm 0.01$ ). A positive and low genetic correlation was observed between MW and SC $(0.24 \pm 0.04)$. A negative genetic correlation $(-0.19 \pm 0.03)$ was estimated between MW and AFC. Selection to increase weight or weight gains at any age, as well as hip height, will change MW in the same direction. Selection for higher SC may lead to a long-term increase in MW. The $\mathrm{AFC}$ can be included in selection indices to improve the reproductive performance of beef cattle without significant changes in MW.

Key words: Age at first calving; Beef cattle; Hip height; Weight gain; Scrotal circumference

\section{INTRODUCTION}

Most Nellore cattle breeding programs have focused on growth-related traits, including weight measures obtained at young ages [weaning (WW) and yearling weight (YW)] or weight gain at different stages of growth. However, this type of selection may lead to an increase in the size of adult beef cows because of a correlated response (Boligon et al., 2009), which in turn increases the costs of maintenance of these animals (Jenkins and Ferrell, 1994). Therefore, large females are undesired, especially in the case of production systems in which cattle are fed exclusively on pasture.

In some Nellore breeding programs (PMGRN/Programa Nelore, 2011), mature cow weight (MW) is already used for genetic evaluations, but selection for this trait is still limited. Therefore, knowledge about genetic correlations between the main traits included in beef cattle selection indices and mature weight is important to determine whether current selection practices will result in heavier mature females due a correlated response.

Within this context, one aspect that needs to be investigated is the possible genetic association between indicator traits of male and female reproductive efficiency and mature weight. In studying Nellore animals, Boligon et al. (2010a) reported a low but favorable $(-0.14)$ genetic association between age at first calving and MW. According to these authors, it is expected that the inclusion of age at first calving in selection indices will improve female reproductive performance without changes in the mature weight of beef cows.

In addition to the possibility of including mature weight in selection indices for herds in which a desired size of the animals needs to be maintained, the inclusion of hip height in the beef cattle selection criteria has been suggested over the past few years to select animals based on size (Vargas et al., 2000; Yokoo et al., 2007). However, little is known about the magnitude of the genetic correlations between mature weight and hip height obtained at weaning and yearling.

The objective of the present study was to estimate the heritabilities and genetic correlations of MW with productive traits (WW, YW, weight gain from birth to weaning (GBW) and from weaning to yearling (GWY), and hip height at weaning and yearling) and indicator traits of sexual precocity (scrotal circumference (SC) and age at first calving (AFC)) to determine whether mature weight responds to selection, but mainly to evaluate the genetic associations of mature weight with growth and sexual precocity indicator traits commonly employed in genetic evaluation programs. 


\section{MATERIAL AND METHODS}

\section{Data description}

Data from 127,104 Nellore animals born between 1993 and 2006, belonging to Agropecuária Jacarezinho Ltda., Valparaíso, São Paulo, were used. The following traits were studied: MW, WW, YW, GBW, GWY, WHH, YHH, SC, and age at first calving (AFC).

The animals are weighed periodically, evaluated and selected. Weight recordings are performed at birth, weaning (205 days of age), and yearling (550 days of age) when $\mathrm{SC}$ is also measured. With respect to reproductive management, females participate in two breeding seasons: one anticipated season ranging from February to March during which 15- to 16-month-old heifers are exposed to bulls to identify sexually precocious animals. The second breeding season starts in the second half of November and lasts 60 days. All females of the herd participate in this breeding. Heifers that do not conceive during the anticipated breeding season are again exposed in the following season. Females that do not conceive in the second breeding season are culled.

MW was measured immediately after calving and was defined as the first weight obtained after 4 years of age. AFC (in days) was calculated as the difference between the date of first calving and the date of birth of the female. WHH and YHH (in $\mathrm{cm}$ ) were measured with a hippometer as the distance of the midplane between the hip bones, at a point between the last lumbar vertebra and first sacral vertebra immediately before the sacral bone, and the floor. GBW and GWY were calculated as the difference between WW and birth weight, and between YW and $\mathrm{WW}$, respectively.

\section{Analysis}

The contemporary group (CG) for MW consisted of animals of the same herd, year of birth, management group at yearling, and year and season of recording. For WW, GBW and WHH, CG consisted of animals of the same herd, year and season of birth, management group at birth and weaning, and sex. For YW, GWY and YHH, CG included the traits until weaning and management group at yearling. CG for SC and AFC included herd, year and season of birth, and management group at birth, weaning and yearling. In addition, the type of service (artificial insemination or natural breeding) was included in CG for AFC. For all traits, records that were outside the interval given by the mean $\mathrm{CG} \pm$ three standard deviations and CG with fewer than four records were excluded. The general structure of the dataset is shown in Table 1.

Heritabilities and genetic correlations were estimated by the restricted maximum likelihood method in multi-trait analysis using the WOMBAT program (Meyer, 2006). The general model used can be described as follows:

$$
y=\mathrm{X} \beta+Z_{1} a+Z_{2} m+Z_{3} p+e
$$

where $y$ is a vector of observations; $b$ is a vector of fixed effects; $a$ is a vector of direct additive genetic effects; $m$ is a vector of maternal genetic effects; $p$ is a vector of maternal permanent environmental effects; and $e$ is a vector of residual random errors associated with the observa- 
tions. $X, Z_{1}, Z_{2}$ and $Z_{3}$ are incidence matrices relating $b, a, m$ and $p$ to $y$. It was assumed that $\mathrm{E}[\mathrm{y}]=\mathrm{Xb} ; \operatorname{Var}(\mathrm{a})=\mathrm{A} \otimes \Sigma a, \operatorname{Var}(\mathrm{m})=\mathrm{A} \otimes_{\Sigma m}, \operatorname{Var}(\mathrm{p})=\mathrm{I}_{\mathrm{Nm}} \otimes_{\Sigma p}$, and $\operatorname{Var}(\mathrm{e})=\mathrm{I}_{\mathrm{N}} \otimes_{\Sigma e}$, where $\Sigma a$ is a direct additive genetic (co)variance matrix between traits; $\Sigma m$ is a maternal additive genetic (co)variance matrix; $\Sigma p$ is a maternal permanent environmental (co)variance matrix; $\Sigma e$ is a residual (co)variance matrix; $A$ is a relationship matrix; $I$ is an identity matrix; $N_{\mathrm{m}}$ is the number of dams of animals with records; $N$ is the number of animals with records, and $\otimes$ is the direct product between matrices. Maternal additive genetic and permanent environmental effects were limited to traits obtained until weaning (WW, GBW, and WHH). The covariances between direct and maternal additive genetic effects were considered to be zero as suggested by Meyer (1997) and Albuquerque and Meyer (2001). The CGs were included as fixed effects and the linear and quadratic effects of age of animal at recording (except for AFC, GBW, and GWY) and age of dam at calving (except for MW) as covariates. For GBW and GWY, the number of days from birth to weaning and from weaning to yearling, respectively, was also included as covariate.

\section{RESULTS AND DISCUSSION}

The means observed for growth traits (Table 1) were very close to those reported in the literature for Nellore cattle (Silva et al., 2003; Boligon et al., 2008a; Pedrosa et al., 2010). These results show the medium size of Nellore animals, which is important for the adaptation of the breed in tropical regions and extensive production systems, since larger animals tend to have less heat tolerance and more maintenance requirements.

Table 1. Number of observations (N), means and respective standard deviation (SD), number of dams (No. dams) and sires (No. sires), and contemporary groups (CG) for the traits studied.

\begin{tabular}{lrrrrr}
\hline Traits & \multicolumn{1}{c}{ N } & Means \pm SD & No. dams & No. sires \\
MW (kg) & 3260 & $434.59 \pm 45.15$ & 3036 & 46 & 46 \\
WW (kg) & 126,807 & $171.13 \pm 25.97$ & 43,971 & 488 & 2318 \\
YW (kg) & 47,609 & $268.09 \pm 39.47$ & 22,000 & 390 & 1562 \\
GBW (kg) & 74,656 & $141.58 \pm 25.56$ & 28,547 & 441 & 1242 \\
GWY (kg) & 47,251 & $95.40 \pm 30.21$ & 21,959 & 390 & 165 \\
WHH (cm) & 13,788 & $117.28 \pm 4.52$ & 9774 & 185 & 350 \\
YHH (cm) & 13,672 & $133.04 \pm 5.48$ & 12,044 & 347 & 621 \\
SC (cm) & 17,833 & $26.11 \pm 3.10$ & 17,301 & 379 & 1970 \\
AFC (days) & 25,590 & $1,056.43 \pm 87.93$ &
\end{tabular}

$\mathrm{MW}=$ mature weight; $\mathrm{WW}=$ weaning weight; $\mathrm{YW}=$ yearling weight; $\mathrm{GBW}=$ weight gain from birth to weaning; $\mathrm{GWY}=$ weight gain from weaning to yearling; $\mathrm{WHH}=$ weaning hip height; $\mathrm{YHH}=$ yearling hip height; $\mathrm{SC}=$ scrotal circumference; $\mathrm{AFC}=$ age at first calving.

The variance components and heritabilities estimated for the traits studied are shown in Table 2. The estimated heritability for MW was $0.43 \pm 0.02$, indicating that this trait can be modified by selection. However, since mature weight is measured relatively late and only in a part of the animals born, the inclusion of the trait in selection indices will depend on the objectives of each property.

The heritability estimated for MW in the present study was similar to that reported in the literature when a single weight record obtained close to a certain age considered to be adult age was used, with estimates ranging from 0.36 to 0.54 (Mercadante et al., 2004; CastroPereira et al., 2007; Pedrosa et al., 2010; Boligon et al., 2010a). Similarly, studies using re- 
peated measures of mature cow weight have reported heritabilities ranging from 0.41 to 0.53 (Kaps et al., 1999; Mercadante et al., 2004; Boligon et al., 2008a).

\begin{tabular}{|c|c|c|c|c|c|c|}
\hline Trait & $\sigma_{a}^{2}$ & $\sigma_{\mathrm{m}}^{2}$ & $\sigma_{\mathrm{c}}^{2}$ & $\sigma_{\mathrm{e}}^{2}$ & $\mathrm{~h}_{\mathrm{a}}^{2}$ & $\mathrm{~h}^{2}{ }_{\mathrm{m}}$ \\
\hline$\overline{\mathrm{MW}}$ & 789.52 & - & - & 1034.21 & $0.43 \pm 0.02$ & - \\
\hline WW & 106.58 & 31.82 & 48.32 & 139.18 & $0.33 \pm 0.01$ & $0.10 \pm 0.01$ \\
\hline YW & 220.08 & - & - & 393.92 & $0.36 \pm 0.01$ & - \\
\hline GBW & 71.11 & 28.92 & 39.35 & 116.57 & $0.28 \pm 0.02$ & $0.11 \pm 0.01$ \\
\hline GWY & 91.59 & - & - & 199.27 & $0.31 \pm 0.01$ & - \\
\hline WHH & 5.12 & 0.78 & 0.39 & 5.44 & $0.44 \pm 0.02$ & $0.07 \pm 0.02$ \\
\hline YHH & 6.11 & - & - & 6.67 & $0.48 \pm 0.02$ & - \\
\hline $\mathrm{SC}$ & 3.32 & - & - & 4.24 & $0.44 \pm 0.01$ & - \\
\hline $\mathrm{AFC}$ & 142.70 & - & - & 765.30 & $0.16 \pm 0.03$ & - \\
\hline
\end{tabular}

In general, studies using MW have shown that the use of a single weight measure close to a certain age may result in a selected sample since part of the females have usually been culled at this age. As suggested by Meyer (1995) and Kaps et al. (1999), traits obtained before selection, which is performed at weaning and yearling in the herd studied, were included in the present study to reduce possible effects of selection on mature weight.

The magnitude of the direct heritabilities estimates for WW and YW was close to that reported in the literature for Nellore animals, which ranges from 0.26 to 0.34 and from 0.34 to 0.48, respectively (Yokoo et al., 2007; Boligon et al., 2008b, 2009). Similarly, the heritability of maternal genetic effects for WW was also close to the range reported in the literature $(0.10$ to 0.14) (Yokoo et al., 2007; Boligon et al., 2008b, 2009). The direct heritabilities estimates for GBW and GWY were of medium magnitude. In studying pre- and post-weaning weight gains in Nellore animals defined as gains from 100 to 300 days of age and from 300 to 600 days, respectively, Holanda et al. (2004) estimated direct heritabilities of 0.23 (pre-weaning weight gain) and 0.06 (post-weaning weight gain) by single-trait analysis.

Estimates of direct heritabilities of medium magnitude were obtained for WHH and YHH (Table 2). For the Nellore breed, Silva et al. (2003), Yokoo et al. (2007) and Pedrosa et al. (2010) obtained direct heritabilities for YHH of $0.30,0.63$ and 0.35 , respectively. In contrast, Vargas et al. (2000) reported high direct heritabilities for WHH (0.73) and YHH (0.87) in Brahman cattle. The maternal heritability for WHH estimated in the present study was similar to that (0.10) reported by Vargas et al. (2000).

The heritability for SC was of medium magnitude, suggesting that a substantial part of the variation in this trait is determined by the additive action of genes, and that $\mathrm{SC}$ can be altered by selection. Reproductive traits are economically important for beef cattle systems, and in order to improve reproductive performance, $\mathrm{SC}$ is currently part of selection indices in most of the Brazilian Nellore breeding programs. This estimate was within the range reported in the literature for Nellore animals (0.30 to 0.53) (Silva et al., 2000; Pereira et al., 2002; Yokoo et al., 2007; Boligon et al., 2010b). 
The heritability for AFC $(0.16 \pm 0.03)$ obtained in the present study was similar to those reported in the literature for Zebu breeds, with estimates ranging from 0.12 to 0.17 (Silva et al., 2000; Boligon et al., 2008b, 2010a). In studying Nellore animals, Pereira et al. (2002) found a lower heritability for AFC of females exposed at 26 months of age (0.02) compared to those exposed at 14 months of age (0.19). According to these authors, the age at which females are exposed for breeding changes the genetic variability of AFC. This variability tends to be higher when females are exposed for breeding at younger ages (at about 14 months). In the present study, although females were exposed at a mean age of 16 months, the short breeding season (60 days) may have impaired the detection of differences between age at puberty of heifers.

In general, the direct heritability of medium magnitude estimated for WW, YW, GBW, GWY, WHH, YHH, and SC suggests that individual selection for these traits will be effective. The low direct heritability estimated for AFC indicates small additive genetic variability in the expression of this trait in the population studied. For maternal genetic effects, the estimated heritabilities (Table 2) were similar to those reported in the literature (Vargas et al., 2000; Yokoo et al., 2007; Boligon et al., 2009).

The genetic correlations between MW and weights recorded at younger ages were positive and ranged from medium to high (Table 3). These correlations are similar to those reported in the literature for Zebu breeds, which range from 0.54 to 0.63 (MW x WW) and from 0.62 to 0.80 (MW x YW) (Mercadante et al., 2004; Castro-Pereira et al., 2007; Boligon et al., 2009; Pedrosa et al., 2010).

\begin{tabular}{|c|c|c|}
\hline Trait & Genetic correlation & Phenotypic correlation \\
\hline WW & $0.63 \pm 0.01$ & $0.41 \pm 0.02$ \\
\hline YW & $0.71 \pm 0.01$ & $0.49 \pm 0.02$ \\
\hline GBW & $0.47 \pm 0.03$ & $0.36 \pm 0.01$ \\
\hline GWY & $0.58 \pm 0.02$ & $0.26 \pm 0.02$ \\
\hline WHH & $0.60 \pm 0.02$ & $0.33 \pm 0.03$ \\
\hline YHH & $0.65 \pm 0.01$ & $0.35 \pm 0.02$ \\
\hline $\mathrm{SC}$ & $0.24 \pm 0.04$ & $0.19 \pm 0.03$ \\
\hline $\mathrm{AFC}$ & $-0.19 \pm 0.03$ & $-0.16 \pm 0.02$ \\
\hline
\end{tabular}

Positive and moderate genetic correlations were observed between MW and weight gains (Table 3), indicating that selection for weight gain should also result in an increase of MW, although to a lesser extent than that expected if selection were to include weights obtained at young ages. However, selection based on weight gains instead of weights obtained at young ages is an alternative to reduce the effect of selection for growth on MW. Using data from Nellore animals, Boligon et al. (2010a) obtained positive genetic correlations of medium magnitude between MW and weight gains from weaning to 12 months of age and from 12 to 18 months of age ( 0.30 and 0.32 , respectively).

In general, the magnitude of the genetic correlations estimated in the present study between MW and traits commonly included in selection indices (weight gains and WW) is relevant since the selection of animals with higher weight gains and/or higher WW may result 
in larger animals at adult age because of a correlated response (Boligon et al., 2009, 2010a). According to Silveira et al. (2004), in the specific case of females, this type of selection may also reduce reproductive efficiency due to a longer growth phase, delaying the onset of reproductive events. In addition, a heavier weight at adult age will lead to greater maintenance requirements which, in turn, will result in longer calving intervals.

The genetic correlations of MW with $\mathrm{WHH}$ and $\mathrm{YHH}$ were positive and moderate $(0.60 \pm 0.02$ and $0.65 \pm 0.01)$. Using data from Nellore animals, Pedrosa et al. (2010) reported a genetic correlation of 0.55 between MW and YHH. The authors suggested the use of direct measurement of the trait or of $\mathrm{HH}$ of the animals itself for a better control of the evolution of mature weight.

The results of the present study suggest that the selection of animals for moderate WHH and/or YHH may be advantageous in extensive rearing systems since this type of selection is a good alternative to control for size and, consequently, for MW in beef cattle. However, studies investigating the genetic correlations between $\mathrm{HH}$ and $\mathrm{MW}$ in beef cattle are scarce in the literature and further investigations using data from different herds need to be conducted.

The low genetic association between MW and SC $(0.24 \pm 0.04)$ indicates that the selection of males for higher SC may lead to long-term increases in MW. On the other hand, a negative and low genetic correlation (-0.17) between MW and SC measured at 12 months of age has been reported by Silva et al. (2000) for Canchim animals. According to these authors, selection for higher SC does not interfere with MW, a highly favorable condition.

The present results indicate a low genetic correlation between MW and AFC (Table 3). Therefore, AFC can be included in selection indices to improve the reproductive performance of beef cows without important changes in female adult size. Similarly, Boligon et al. (2010a) found a negative and low genetic correlation $(-0.14)$ between MW and AFC in Nellore females.

The results of the present study suggest that indicator traits of sexual precocity (SC and AFC) are not strongly correlated with MW. On the other hand, selection for higher weights and weight gains obtained at young ages to increase the productivity of the herd should be performed in such a way that prevents increases in MW, which is possible if these traits are used simultaneously in genetic breeding programs.

\section{CONCLUSIONS}

The growth traits studied and SC show genetic variability in Nellore cattle and can be included in genetic breeding programs designed to improve these traits. The inclusion of weight, weight gain and hip height obtained at young ages in selection indices may increase MW. As a consequence, mature weight needs to be included in selection indices to maintain an adult size of beef cows that is adequate for the production system. Selection for higher SC may lead to a long-term increase in MW. The AFC can be included in selection indices to improve reproductive performance in beef cattle without important changes in MW.

\section{ACKNOWLEDGMENTS}

Research supported by Fundação de Amparo à Pesquisa do Estado de São Paulo (FAPESP). We are indebted to Agropecuária Jacarezinho for the use of the dataset. 


\section{REFERENCES}

Albuquerque LG and Meyer K (2001). Estimates of direct and maternal genetics effects for weights from birth to 600 days of age in Nelore cattle. J. Anim. Breed. Genet. 118: 83-92.

Boligon AA, Albuquerque LG, Mercadante ME and Lobo RB (2008a). Models for genetic evaluation of Nelore cattle mature body weight J. Anim. Sci. 86: 2840-2844.

Boligon AA, Albuquerque LG and Rorato PRN (2008b). Associações genéticas entre pesos e características reprodutivas em rebanhos da raça Nelore. Rev. Bras. Zootec. 37: 596-601.

Boligon AA, Albuquerque LG, Mercadante MEZ and Lobo RB (2009). Herdabilidades e correlações entre pesos do nascimento à idade adulta em rebanhos da raça Nelore. Rev. Bras. Zootec. 38: 2320-2326.

Boligon AA, Albuquerque LG, Mercadante MEZ and Lobo RB (2010a). Study of relations among age at first calving, average weight gains and weights from weaning to maturity in Nellore cattle. Rev. Bras. Zootec. 39: 746-751.

Boligon AA, Silva JA, Sesana RC, Sesana JC, et al. (2010b). Estimation of genetic parameters for body weights, scrotal circumference, and testicular volume measured at different ages in Nellore cattle. J. Anim. Sci. 88: 1215-1219.

Castro-Pereira VMC, Alencar MM and Barbosa PF (2007). Estimativas de parâmetros genéticos e de ganhos direto e indireto à seleção para características de crescimento de machos e fêmeas da raça Canchim. Rev. Bras. Zootec. 36: 1037-1044.

Holanda MCR, Barbosa SBP, Ribeiro AC and Santoro KR (2004). Tendências genéticas para crescimento em bovinos Nelore em Pernambuco, Brasil. Arch. Zootec. 53: 185-194.

Jenkins TG and Ferrell CL (1994). Productivity through weaning of nine breeds of cattle under varying feed availabilities: I. Initial evaluation. J. Anim. Sci. 72: 2787-2797.

Kaps M, Herring WO and Lamberson WR (1999). Genetic and environmental parameters for mature weight in Angus cattle. J. Anim. Sci. 77: 569-574.

Mercadante MEZ, Razook AG, Trovo JBF, Cyrillo JNSG, et al. (2004). Parâmetros genéticos do peso no início da estação de monta, considerado indicativo do peso adulto de matrizes Nelore. Rev. Bras. Zootec. 33: 1135-1144.

Meyer K (1995). Estimates of genetic parameters for mature weight of Australian beef cows and its relationship to early growth and skeletal measures. Livest. Prod. Sci. 44: 125-137.

Meyer K (1997). Estimates of genetic parameters for weaning weight of beef cattle accounting for direct-maternal environmental covariances. Livest. Prod. Sci. 52: 187-199.

Meyer K "WOMBAT" (2006). Digging Deep for Quantitative Genetic Analyses by Restricted Maximum Likelihood. Proccedings of 8th World Congress of Genetic and Applied Livestock Production, Belo Horizonte.

Pedrosa VB, Eler JP, Ferraz JBS, Silva JAV, et al. (2010). Parâmetros genéticos do peso adulto e características de desenvolvimento ponderal na raça Nelore. Rev. Bras. Saúde Prod. An. 11: 104-113.

Pereira E, Eler JP and Ferraz JBS (2002). Análise genética de características reprodutivas na raça Nelore. Pesq. Agropec. Bras. 37: 703-708.

PMGRN/Programa Nelore (2011). Sumário. Available at [http://www.ancp.org.br]. Accessed February 22, 2011.

Silva AM, Alencar MM, Freitas AR, Barbosa RT et al. (2000). Herdabilidades e correlações genéticas para peso e perímetro escrotal de machos e características reprodutivas e de crescimento de fêmeas, na raça Canchim. Rev. Bras. Zootec. 29: 2223-2230.

Silva JAV, Van Melis MH, Eler JP and Ferraz JBS (2003). Estimação de parâmetros genéticos para probabilidade de prenhez aos 14 meses e altura na garupa em bovinos da raça Nelore. Rev. Bras. Zootec. 32: 1141-1146.

Silveira JC, McManus C, Mascioli AS, Silva LOC, et al. (2004). Fatores ambientais e parâmetros genéticos para características produtivas e reprodutivas em um rebanho Nelore no estado do Mato Grosso do Sul. Rev. Bras. Zootec. 33: $1432-1444$

Vargas CA, Elzo MA, Chase Jr CC and Olson TA (2000). Genetic parameters and relationships between hip height and weight in Brahman cattle. J. Anim. Sci. 78: 3045-3052.

Yokoo MJ, Albuquerque LG, Lobo RB, Sainz RD, et al. (2007). Estimativas de parâmetros genéticos para altura do posterior, peso e circunferência escrotal em bovinos da raça Nelore. Rev. Bras. Zootec. 36: 1761-1768. 